\title{
AS CONTRIBUIÇÕES DA INTERVENÇÃO MULTIPROFISSIONAL NA OBESIDADE INFANTIL NO CONTEXTO DE VIOLÊNCIA URBANA ${ }^{1}$
}

\section{THE CONTRIBUTIONS OF MULTIDISCIPLINARY INTERVENTION IN CHILDHOOD OBESITY IN THE CONTEXT OF URBAN VIOLENCE}

\author{
Teófilo Antonio Máximo Pimenta ${ }^{2}$ \\ Igor Moreira Dias Pereira ${ }^{3}$
}

\begin{abstract}
RESUMO
A obesidade é classificada como epidemia, seu crescimento, especialmente entre crianças brasileiras, está associada a fatores ambientais, como: a globalização, ao processo de urbanização, a violência urbana e aodesenvolvimento tecnológico. Desta forma, utilizando um método descritivo e qualitativo o objetivo deste estudo foi discutir os fatores ambientais da obesidade infantil, analisar o processo de estigmatização social da obesidade, apontar as várias formas de violência que o indivíduo obeso enfrenta na sociedade contemporânea brasileira e apresentar as contribuições de uma equipe multiprofissional de intervenção da doença em questão. Por fim, o presente artigo apontou que entre as crianças obesas há um demasiado consumo de produtos industrializados, horas em frente à televisão e o videogame, ritmo de vida acelerado, poucas políticas públicas e privadas de estímulo à atividade física. As intervenções da equipe multiprofissional trouxeram contribuições nos aspectos biológicos, psicológicos e sociais das crianças em processo de tratamento da obesidade.
\end{abstract}

Palavras-chave: Obesidade. Violência urbana. Tratamento multiprofissional. Crianças.

\begin{abstract}
Obesity is classified as an epidemic. Their growth, especially among Brazilian children, is associated with environmental factors such as globalization, the process of urbanization, urban violence and technological development. Thus, the aim of this study was to discuss the environmental factors in childhood obesity, analyze the process of social stigmatization of obesity, pointing out the various forms of violence that the obese individual faces in contemporary Brazilian society and present contributions of a multidisciplinary intervention team the disease in question. Finally, this article pointed out that among obese children there is too much consumption of manufactured products, hours in front of television and video games, fast pace of life, few public and private policies to encourage physical activity. Thus, interventions multidisciplinary team brought contributions in the biological, psychological and social needs of children in the process of treating obesity issues.
\end{abstract}

Keywords: Obesity. Urban violence. Multidisciplinary treatment. Children.

1 Este artigo é parte da dissertação de mestrado do primeiro autor intitulada "Tratamento Multiprofissional: As limitações e potencialidades da intervenção na obesidade infantil" e defendida em 2013.

2 Mestre em Desenvolvimento Humano: Formação, Políticas e Práticas Sociais pela Universidade de Taubaté. E-mail:tpimenta@yahoo.com.br

3 Mestrando em Políticas Sociais pela Universidade Cruzeiro do Sul. E-mail: rolucig@yahoo.com.br 


\section{INTRODUÇÃO}

As consequências da violência urbana, na qual tem esvaziado as ruas e os espaços públicos, confinando crianças em suas casas, têm levado a um maior uso da tecnologia, como os computadores, videogames e televisores. (FRAGOSO 2009).

Estudos de Malina e Silva (2003) explicam a relação existente entre indivíduos sobrepesos e o tempo prolongado na frente à televisão, associando o tempo diário em que a criança brasileira passa assistindo aos programas de televisão com o baixo nível de atividade física, elegendo esses fatores como os que contribuem para a ocorrência do sobrepeso e obesidade infantil. Oliveira et al. (2003, p. 149) ressaltam que "as comodidades que o mundo moderno oferece como possibilidade do uso de TV, telefones, videogames, computadores entre outros, [...], conduzem também a um estilo de vida sedentário." Neste âmbito o uso da tecnologia e o estilo de vida podem ser gerados pela violência urbana.

Desta forma, as questões macrossociais relacionadas às intervenções das políticas públicas de saúde e segurança seriam importantes para se buscar um entendimento do crescimento da obesidade infantil.

No Brasil, a obesidade infantil alcança números epidêmicos, os dados apresentados pelo Instituto Brasileiro de Geografia e Estatística (2010) apontam que 1 em cada 3 crianças brasileiras de 5 a 9 anos estão acima do peso recomendado pela Organização Mundial da Saúde. Segundo Santos e Scherer (2012) o Brasil baseia suas alternativas no enfrentamento da obesidade em formulações de ações que visam à prevenção e tratamento. Tais reflexões que em um primeiro momento tinham uma exclusividade do campo da saúde, atualmente observa-se uma ampliação para outros campos do conhecimento.

Devido aos números crescentes da obesidade infantil há a necessidade de implementação de medidas e ações, como:

[...] a ampliação de políticas de saúde que envolvam educação nutricional, o desenvolvimento de infraestrutura apropriada para práticas recreativas e de atividade física, o desenvolvimento de legislação apropriada para rotulagem e mídia e, por fim, a participação compartilhada do setor de saúde com os setores de educação, social e de esportes [...]"
(SOCIEDADE BRASILEIRA DE PEDIATRIA, 2008, p. 42).

Essas medidas e ações em combate à epidemia de obesidade infantil conforme recomendam Reis et al. (2011) as políticas públicas e ações intersetoriais devem proporcionar ambientes estimuladores, que apoiem e mantenham padrões saudáveis de alimentação e atividade física, enfatizando que tais atitudes deveriam ir além de informar e educar a população.

Desta forma, este artigo tem como objetivo discutir os fatores ambientais da obesidade infantil, analisar o processo de estigmatização social da obesidade, apontar as várias formas de violência que enfrenta o indivíduo obeso na sociedade contemporânea brasileira e apresentar as contribuições de uma equipe multiprofissional de intervenção da doença em questão.

\section{CONTEXTO SOCIOCULTURAL DA OBESIDADE}

A obesidade é caracterizada como uma doença multifatorial em que as causas podem ser atribuídas a fatores, dentre eles: genéticos, psicológicos, clínicos e socioculturais. Principalmente entre as crianças a obesidade está relacionada aos fatores socioculturais como: o demasiado consumo de produtos industrializados, as horas em frente à televisão e o videogame, o ritmo de vida acelerado e poucas políticas públicas de estímulo à atividade física contribuíram para o agravamento da obesidade.

O crescimento da obesidade infantil vem atrelado aos fatores socioculturais, associação de hábitos sedentários, a ausência de segurança, a pressão pelo consumo alimentar desregrado e as mudanças nas estruturas das famílias contemporâneas.

No entanto, dois estudos importantes observaram fatores endógenos na prevalência da obesidade infantil. Salve (2006) verificou que em filhos de pais obesos as chances das crianças se tornarem obesas são de $80 \%$, se um dos pais for obeso a chance cai para $40 \%$ e se ambos os pais não forem obesos a criança tem apenas $10 \%$ de probabilidade de se tornar obesa; e Roschel et al. (2006, p. 98) apontou que em "[...] gêmeos monozigóticos de pais obesos mostram que o fator ambiental pode ser predominante aos fatores genéticos na determinação da quantidade de gordura corporal $[\ldots]$ ". 
Considera-se importante os fatores endógenos, porém em razão da maior concentração de casos de obesidade influenciados pelos fatores exógenos, o foco do presente estudo segue nesta direção. Assim, apreender as influências dos possíveis determinantes sociais, históricos e culturais na obesidade infantil será importante para entender a origem do problema no Brasil.

Quanto à influência dos fatores sociais, históricos e culturais na obesidade infantil apontou-se que a alimentação rica em açúcares simples e gorduras, o estilo de vida sedentário e os avanços tecnológicos, como videogames, computadores, poderiam ser os motivos de uma maior prevalência da obesidade. (OLIVEIRA; FISBERG, 2003, p. 107-108).

Para Pinho e Petroski (1999, p. 62) "atitudes cotidianas buscam cada vez mais a economia do esforço físico, provocando desequilíbrio entre a ingestão alimentar e o consumo de energia, o que facilita o aumento consequente de acúmulo da adiposidade corpórea".

A partir do século $\mathrm{XX}$, houve um aumento desse hábito alimentar devido ao aumento das porções dos alimentos ingeridos nos Estados Unidos (OLIVEIRA; FISBERG, 2003) e a globalização das grandes empresas de alimentos, logo o comportamento da cultura norte americana estava sendo repercutido, reproduzido e incorporado por outras culturas, inclusive a brasileira.

De acordo com Moraes (2010) houve momentos sócio-históricos que são especificidades do caso brasileiro e que foram influenciadores no processo de crescimento do problema, como o rápido êxodo rural, a instituição em 1940 do salário mínimo baseado no valor da cesta básica, o crescente processo de industrialização ocorrido a partir de 1970, a entrada da mulher no mercado de trabalho, alterando a dinâmica das famílias e a criação do Plano Real em $1994^{4}$.

A partir dos anos 90, segundo Mendonça e Anjos (2004) no país iniciou-se o crescimento da oferta de refeições rápidas (fast food), aumentou-se o número de restaurantes e ampliou-se o uso de

\footnotetext{
4 Com a criação do Plano Real em 1994, ocorreram mudanças econômicas aumentando o poder de compra da população, principalmente a de baixa renda. No mesmo período, segundo Moraes (2010) pode ser observado aumento da renda per capita da população e diminuição nos preços dos alimentos de alto teor calórico.
}

alimentos industrializados/processados ${ }^{5}$. Dâmaso et al. (2003, p. 6-7) analisa que esta "revolução alimentar" gerou mudanças de hábitos alimentares importantes na sociedade brasileira, que "[...] devido a alterações no estilo de vida, passou a ter menos tempo para realizar suas refeições de forma adequada e balanceada; em vez disso, recorre-se a fast food, normalmente ricos em gordura e com valor calórico acima do necessário."

Para Mendonça e Anjos (2004) estas mudanças foram significativas, especialmente no padrão da alimentação tradicional do brasileiro. Ao mesmo tempo inaugurou-se um novo estilo de vida, mais moderno e urbano.

Outro fato relevante da década de 1990 levantado por Moraes (2010) foi o aumento no consumo de produtos industrializados como os congelados, os salgadinhos, refrigerantes e biscoitos, principalmente pelas famílias de menor poder aquisitivo. Observou-se na mesma década um declínio no consumo de legumes, hortaliças e frutas, e um aumento vertiginoso de residências com televisão no Brasil (MENDONÇA; ANJOS, 2004). Estes indicativos são importantes e devem ser levados em consideração como possíveis contribuidores do avanço da obesidade em especial nas crianças de baixa renda no Brasil, sendo a televisão uma forma de lazer dessa população.

Viuniski (2003, p. 23) alertou que "enquanto o preço das frutas e verduras for maior do que o de balas e biscoitos e enquanto um litro de leite custar mais do que um litro de refrigerante, não teremos nutrição adequada nas camadas mais carentes da sociedade".

Como menciona Silva (2007) a partir da década de 1980, ocorre uma proliferação de academias de ginásticas, principalmente nos grandes centros urbanos do Brasil, com este movimento inaugura-se uma responsabilização individual pela saúde e aparência física.

As mudanças nos padrões estéticos e de saúde foram um processo longo, contínuo e ininterrupto, sendo refletido na nossa sociedade. Assim, Pimenta e Rocha (2012) observaram, em levantamento nos bancos de dados da Pesquisa Nacional sobre Saúde

\footnotetext{
5 Alimentos que precisam ser fritos e que possuem um grande valor energético, porém um pequeno valor nutricional.
} 
e Nutrição/PNSN (1989) e a Pesquisa de Orçamentos Familiares/POF (2008-2009), que nos últimos anos houve no Brasil aumento expressivo na porcentagem de crianças entre 5 e 9 anos com sobrepeso e obesidade. A pesquisa mencionada analisou 20 anos, período sócio-histórico relativamente curto, porém, os reflexos dessas mudanças na sociedade brasileira são sentidos até os dias atuais. No entanto, conforme demonstrado é um processo que vem ocorrendo muito antes.

Os aspectos apresentados são fundamentais para pensar a especificidade e evolução do sobrepeso e da obesidade no Brasil. O desenvolvimento do capitalismo, o crescimento demográfico, o desenvolvimento tecnológico, o processo de industrialização, a violência urbana, o pouco estímulo à prática de atividade física contribuíram para a emergência da obesidade como problema de saúde pública mundial e colaboram para a manutenção e crescimento do problema. A obesidade se constitui rapidamente numa epidemia e caminha, ou "já é caracterizada para muitos como uma pandemia" (LANCHA JÚNIOR; LANCHA, 2006, p. 2).

\section{VIOLÊNCIA E PROCESSO DE ESTIGMATIZAÇÃO DA CRIANÇA OBESA: UM BREVE PANORAMA HISTÓRICO}

No início do século XIX a associação da obesidade com atributos positivos sofre forte mudança, sendo que "[...] em 1900 esta representação se inverteu, e de lá para cá o sucesso e a beleza vêm sendo associados à magreza" (STENZEL, 2002, p. 29). Almeida et al. (2005) destacam que o fator sociocultural tem grande parcela de contribuição no referencial de padrão estabelecido, ao longo da história ocorreram mudanças profundas e significativas nas sociedades e, consequentemente, no comportamento das pessoas. Em um dado momento histórico a gordura corporal simbolizava poder, prosperidade, sendo aceitável no meio social.

Para Stenzel (2002) o início da estigmatização social da obesidade ocorreu paralelo ao processo de industrialização, as ideias do cristianismo, ao reconhecimento da nutrição como importante área do conhecimento e as contribuições da moda no referencial de padrão estético. As ideias do cristianismo propagava o jejum como símbolo de purificação e virtude, o excesso alimentar como um pecado, a pri- vação como ato sagrado e as imagens dos seus santos magros; o reconhecimento da nutrição no século XX como importante área de estudo, associando a palavra diet à limitação/restrição de alguns alimentos prejudiciais à saúde; e a moda que contribuiu com seu exacerbado valor estético a magreza, como sendo a única forma de beleza. Dessa forma, essa rede de influência acabou sendo um determinante para o processo de transição de valores atribuídos a obesidade.

A associação da obesidade à doença ocorreu apenas recentemente, segundo Rigo e Santolin (2012) a partir de critérios baseados no Índice de Massa Corporal, em 1998, quando o obeso é classificado oficialmente pelas autoridades de saúde como doente. Dessa forma, a obesidade constitui-se como um problema de saúde pública a ser solucionado. Os referidos autores resumem o sentimento do indivíduo obeso na modernidade como:

a incitação do medo provocada pelo conceito de risco associado a uma noção moral, puramente abstrata, de qualidade e expectativa de vida ajuda a forjar no corpo social a verdade de que os obesos não somente são doentes, mas que eles têm a obrigação de emagrecer, inclusive pelos prejuízos que, supostamente, acarretariam aos cofres públicos. (RIGO; SANTOLIN, 2012, p. 282).

No entanto, de acordo com Silva (2007), na sociedade moderna, em que prevalece a cultura ocidental, vem ocorrendo uma forte valorização do corpo magro, esguio, tônus enrijecidos e saudáveis, consequentemente constrói-se estereótipos positivos com relação à magreza. Por outro lado, desvaloriza-se o indivíduo com sobrepeso e/ou obesos, gerando problemas psicossociais, atitudes discriminatórias e preconceito social.

Com o conceito estatístico para definir pessoas normais, não só uma população obesa sofre com a segregação e o preconceito, mas todos os extremos "[...] altos e baixos, magros e gordos, todos os polos são problemáticos e enfrentam dificuldades diárias" (FISBERG, 1995, p. 9).

De acordo com Fischler (1995), atualmente as sociedades possuem traços explícitos de uma cultura lipofóbica ${ }^{6}$ e excludente. Sociedades com esta

\footnotetext{
6 Segundo Claude Fischler (1995) antropólogo francês que desenvolve estudo sobre a cultura alimentar, as culturas lipofóbicas são caracterizadas por um certo horror a gordura corporal e, consequente, estigmatização e preconceito com relação ao indivíduo obeso.
} 
característica são constituídas por pessoas que possuem aversão ao mínimo de gordura corporal, e consequente desenvolvimento de um ódio crescente ao indivíduo obeso. Desta forma, Gonçalves (2004, p. 2-3) explica que "[...] atualmente, o mínimo sinal de gordura é rechaçado. Hoje, se deseja um corpo absolutamente magro, sem adiposidade alguma. Além disso, os referenciais de obesidade e magreza mudaram com o tempo. [...]".

Stenzel (2002, p. 30-31) esclarece que:

[...] a hostilidade com relação à obesidade é parte de um contexto histórico-social bastante amplo que envolve a medicina, a ciência, a arte, a religião, as questões de gênero, a moda, a mídia, como também uma série de códigos éticos e morais.

Ademais, o agravante com relação à obesidade é que o indivíduo acaba sendo culpado pela manutenção da doença e responsável pelo sucesso ou não do tratamento, cabendo a ele buscar as melhores resoluções para o seu problema.

Nos anos 1960, emergiu a ginástica e proliferaram estudos associando o excesso de peso a riscos cardiovasculares, respiratórios e ortopédicos, trazendo uma exacerbada busca por um corpo magro e de forma atlética intensificando o processo de negação da obesidade. Desta forma, a obesidade passa “[...] de padrão de beleza à vilão dos tempos modernos, o obeso é catapultado para a área do preconceito físico sem igual. [...]." (FISBERG, 1995, p. 10).

A obesidade "tem sido apontada como um dos fatores contribuintes para a baixa-estima, isolamento social, a depressão, etc." (SLOCHOWER; KAPLAN, 1980 apud SALVE, 2006, p. 34). Desse modo, a criança obesa pode vir a ter dificuldades de obter prazer nas relações sociais. O desenvolvimento de estereótipos do tipo que o obeso é sem (não tem) força de vontade, preguiçoso e fora de moda, reforça ainda mais o desconforto individual.

Os estereótipos preconceituosos construídos na sociedade e transmitidos pela cultura podem contribuir para que a criança desenvolva uma imagem negativa de si, além disso, as vivências de momentos de discriminação ao longo do desenvolvimento infantil podem gerar momentos de profunda infelicidade. Segundo Mishima e Barbieri (2009, p. 250) "a obesidade provoca efeitos psicológicos na criança deixando marcas durante toda a sua existência".
Para defender-se dos momentos desagradáveis proporcionados pelo convívio, crianças obesas se isolam socialmente, o que poderia ser uma das explicações do aumento da obesidade infantil. Malina e Silva (2003), por sua vez, aponta que a televisão acaba sendo uma das principais opções de lazer para as classes mais pobres, estando presente em praticamente todos os lares brasileiros, não sendo uma realidade exclusiva dos grandes centros urbanos. Fragoso (2009) complementa que a televisão com sua lógica mercadológica contribuiu para formar o consumidor infantil.

Conforme Andrade e Santos (2012) em desenhos animados ${ }^{7}$ exibidos nas décadas de 1980 e 1990 eram ressaltadas nos super-heróis as capacidades, físicas como, agilidade, força, flexibilidade e velocidade; cognitivas como inteligência e autonomia; e os valores, como honestidade. No entanto, os corpos na sua maioria independente do lado (bem ou mau) ou gênero do personagem eram fortes, musculosos, belos e perfeitos. Os autores investigaram as subjetividades imbuídas nesses desenhos e quanto influenciaram no comportamento individual.

Desta forma, o desenho Popeye contribui para a construção de pensamentos com estigmas e a relação aos indivíduos obesos. As tramas desse desenho animado em sua maioria eram as disputas do marinheiro Popeye com Brutus (obeso e maldoso) pelo amor de Olivia Palito. Dudu, o gordinho simpático amigo do Popeye, era um bonachão, glutão e molenga, comilão de hambúrguer que nunca tinha dinheiro. Então, para comer ele trapaceava ou dava calotes. Assim os destaques são para os dois obesos (estigmatizados) do desenho que eram característicos por elementos pejorativos o primeiro era mau e o segundo, apesar de ser amigo e simpático, era comilão e "caloteiro".

Isso mostra que a indústria cultural exerce influências de formas explícitas e implícitas, cria subjetividade nas massas de indivíduos, desta forma, implicitamente na sociedade moderna:

[...] o obeso é aquele que deve ser expurgado do nosso cotidiano, pois atrapalha a velocidade cotidiana, torna menos belos os programas televisivos, entre outras imagens degenerativas. Ao mesmo tempo,

\footnotetext{
7 O referido artigo analisou seis desenhos animados veiculados nas décadas de 1980 e 1990, sendo eles: He-Man, She-Ra, A Caverna do Dragão, Thundercats, Super-Amigos e Popeye.
} 
o obeso serve como exemplo de inadequação, da falta de iniciativa, mas também lembra aquela forma grotesca que serve de inspiração para piadas infantis ou para transmitirmos momentos de riso a um colega através de mais uma imagem "hilária" enviada pela internet [...] (GOMES, 2006, p. 68).

Consequentemente esse tipo de influência pode causar um mal-estar, pois é retratado com uma imagem negativa e uma estigmatização social do indivíduo fora do padrão devido a que são alvos de piadas.

Outros fatores sociais que contribuíram para o aumento dos casos de obesidade infantil na população de baixa renda seria a violência urbana, que nas periferias dos grandes centros urbanos, especificamente em Curitiba, contribuiu para o esvaziamento das praças públicas (TSCHOKE; RECHIA, 2012). Fragoso (2009) afirma que a violência urbana esvaziou as ruas e os espaços públicos aprisionando as crianças em suas casas, furtando a sua infância.

Ao analisar aspectos nutricionais da população de baixa renda, Viuniski (2003, p. 23) aponta que o:

[...] aparente paradoxo mostra apenas as duas caras da mesma moeda. Os pobres ficam desnutridos e anêmicos porque não têm o suficiente para se alimentar, e ficam obesos porque se alimentam mal, com desequilíbrio energético importante.

Oliveira e Fisberg (2003) observaram, entre as crianças no Brasil, nas últimas décadas houve uma transição nutricional, paralelamente ocorreu a diminuição da desnutrição e aumento do sobrepeso e obesidade nesta população.

Para Stenzel (2004 apud LANDEIRO, 2011) atualmente nas sociedades modernas há um paradoxo, do prazer do ato de comer e a obsessão em ter um corpo dentro do padrão aceito socialmente, também uma busca desenfreada para adequar o corpo ao padrão estético dos dias atuais, em alguns casos o indivíduo põe em risco a própria saúde.

Apesar desse paradoxo, há um risco com relação a influência da obesidade sobre o desenvolvimento infantil e uma possibilidade aumentada das crianças obesas tornarem-se adultos obesos. Desta forma, manter a obesidade por toda vida possivelmente pode surgir consequências, como:

insuficiência cardíaca, diabetes, arteriosclerose, hipertensão e aumento da mortalidade. Assim o excesso de peso de $4.5 \mathrm{Kg}$ aumenta em $8 \mathrm{x}$ a probabilidade de mortalidade do indivíduo; um excesso de peso de $9 \mathrm{Kg}$ aumenta a porcentagem de mortalidade em $18 \mathrm{x}$ e assim por diante. (LEDERER, 1991 apud SALVE, 2006, p. 33).

No Quadro 1 pode-se observar que a obesidade infantil está associada a várias complicações biológicas, psicológicas e sociais, e estas podem ou não influenciar a criança no seu desenvolvimento.

\section{PROCEDIMENTO METODOLÓGICO}

Trata-se de uma pesquisa básica, que “[...] objetiva gerar conhecimentos novos úteis para o avanço da ciência sem aplicação prática prevista [...]" (SILVA; MENEZES, 2005, p. 20), e uma Abordagem Qualitativa. Devido ao fato que a obesidade é entendida como doença associada a múltiplos fatores, será por meio desse procedimento que o pesquisador pode compreender as dimensões da doença, do contexto micro (tratamento) ao contexto macro (formulação de políticas públicas).

Neste trabalho foram coletados dados de entrevista " "semi-estruturada" composta por 13 questões, porém foi analisado apenas a que versava sobre "quais as possíveis contribuições no desenvolvimento da criança obesa que você visualiza nas suas intervenções?" Em seguida, foi aplicada individualmente nos cinco profissionais que compunham a equipe multiprofissional na ocasião das entrevistas, sendo-os: uma assistente social, um médico, uma nutricionista, uma professora de educação física, e um psicólogo, no segundo semestre de 2011.

\section{DISCUSSÃO DOS DADOS}

\section{Contribuições de uma equipe multiprofis- sional de intervenção da obesidade infantil}

Para Dâmaso et al. (2003, p. 4) "[...] a obesidade possui uma origem complexa e suas causas específicas indubitavelmente diferem de uma pessoa para outra" para ela o reconhecimento dos múltiplos

\footnotetext{
8 Com relação aos procedimentos de coleta de dados, como sendo parte de uma dissertação de mestrado o presente instrumento foi submetido ao CEP da Universidade de Taubaté/SP, conforme preconiza a resolução do Conselho Nacional de Saúde nº 196/96, sendo aprovado sob a declaração de $n^{\circ} 416 / 11$.
} 
Quadro 1 - Complicações da obesidade

\begin{tabular}{|l|l|}
\hline Articulares & $\begin{array}{l}\text { Maior predisposição a artroses, osteoartrite; } \\
\text { Epifisiólise da cabeça femoral; } \\
\text { Genu valgum, coxa vara. }\end{array}$ \\
\hline Cardiovasculares & $\begin{array}{l}\text { Hipertensão arterial sistêmica; } \\
\text { Hipertrofia cardíaca. }\end{array}$ \\
\hline Cirúrgica & Aumento do risco cirúrgico. \\
\hline Crescimento & $\begin{array}{l}\text { Idade óssea avançada; Aumento da altura; } \\
\text { Menarca precoce. }\end{array}$ \\
\hline Cutâneas & Maior predisposição a micoses; Dermatitese piodermites. \\
\hline Endócrino-metabólicas & $\begin{array}{l}\text { Resistência à insulina e maior predisposição ao diabetes; Hipertrigliceridemia e hipercolester- } \\
\text { olêmica. }\end{array}$ \\
\hline Gastrointestinais & Aumento da frequência de litíase biliar; Esteatose hepática e esteatohepatite. \\
\hline Mortalidade & Aumento do risco de mortalidade. \\
\hline Neoplásicas & Maior frequência de câncer de endométrio, mama, vesícula biliar, cólon/reto e próstata. \\
\hline Psicossociais & $\begin{array}{l}\text { Discriminação social e isolamento; } \\
\text { Afastamento de atividades sociais; Dificuldade de expressar seus sentimentos. }\end{array}$ \\
\hline Respiratórias & $\begin{array}{l}\text { Tendência à hipóxia, devido a aumento da demanda ventilatória, aumento do esforço respiratório, } \\
\text { diminuição da eficiência muscular, diminuição da reserva funcional, microectasias, apneia do } \\
\text { sono, síndrome de Pickwicky; } \\
\text { Infecções; Asma. }\end{array}$ \\
\hline
\end{tabular}

Fonte: Mello et al. (2004)

fatores é importante para o tratamento da obesidade estabelecida e/ou para a prevenção do seu aparecimento, o que sugere que a obesidade é considerada uma doença multifatorial. Sua simplificação ou tratamento por meio de medidas imediatas como restrição no hábito alimentar não é o recomendado:

de fato, a perda de peso pode ser um alento a quem desenvolveu a obesidade, porém não ataca a causa, ou seja, o agente promotor dessa mudança de padrão. Sendo as causas variadas, as soluções também devem ser. Adotar uma dieta que eleja determinado grupo de alimentos como responsável pela obesidade é, sem dúvida, uma abordagem por demais reducionista e não enxerga complexidade do ser humano. (LANCHA JR; LANCHA, 2006, p. 2).

À luz desse pressuposto, verificamos a dimensão do problema e a necessidade de intervenções multiprofissionais no tratamento da criança com sobrepeso e/ou obesa. A equipe multiprofissional deve refletir a construção de estratégias criativas para a resolução do problema de forma coletiva. Objetivar e contemplar a plenitude e complexidade da constituição humana e que seja realizado um trabalho que mude a vida de indivíduos nesta condição, propondo mudanças em todos os contextos do indivíduo, em especial o familiar.
Segundo Segal e Fandiño (2002, p. 68), “a obesidade é uma condição médica crônica de etiologia multifatorial, seu tratamento envolve vários tipos de abordagens. A orientação dietética, a programação de atividade física e o uso de fármacos antiobesidade são os pilares principais do tratamento".

Tal tratamento, segundo Dâmaso et al. (2006), constitui de intervenções clínicas, psicológicas, nutricionais e estímulo a atividade física. $\mathrm{Na}$ intervenção clínica deve-se avaliar o estado clínico de saúde geral, investigar o histórico familiar e da obesidade; nas intervenções psicológicas por meio de consultas deve-se realizar orientação psicoterápica individual ou em grupo; nas intervenções nutricionais deve-se investigar, através de inquéritos de estimativa alimentar e consultas individuais, aspectos quantitativos e qualitativos das alimentações.

É atribuição dos nutricionistas ficarem a disposição das famílias para eventuais informações adicionais; e as intervenções do profissional da educação física devem pautar na orientação do estilo de vida mais ativo e saudável. Cattai et al. (2008) atribuem a esse profissional papel importante no programa de tratamento do sobrepeso e obesidade infantil tendo em vista que o número de evasão ao tratamento é grande, e por meio de atividades lúdico-recreativas 
criam-se estratégias que evitam e/ou minimizam a desistência aos programas voltados a perda de peso. Abaixo se apresentam as contribuições das intervenções fragmentadas dos cinco profissionais que compõe a equipe de trabalho multiprofissional de intervenção da obesidade.

\section{Educação Física}

A maior contribuição do profissional de educação física foi promover o gosto pela atividade física nas crianças, motivá-las a praticar atividade física, incentivá-las a participação de forma efetiva, mostrando-lhes a importância da atividade física na promoção e prevenção da saúde e no controle da gordura e peso corporal. Desta forma, o referido profissional destaca sua contribuição por meio do diálogo da importância da atividade física nos diferentes contextos, neste caso em específico programa e escola:

\begin{abstract}
falo bastante da questão da participação, cobro muito a participação efetiva deles na educação física aqui (programa) e na escola.
\end{abstract}

\section{Medicina}

O profissional de medicina ressalta que dentro da sua área já há uma gama de estudos voltados à obesidade, pelo falto do interesse da disciplina e pela alta prevalência atual, fazendo parte do dia a dia de atendimento de um endocrinologista de uma forma geral. Segundo o referido profissional sua contribuição é no controle:

[...] das comorbidade que acompanham, às vezes, alterações lipídicas, glicêmicas, síndrome metabólica e pressão arterial.

Este profissional finaliza apontando que: grande parte do volume de atendimento de um endocrinologista em geral é a obesidade.

\section{Nutrição}

Para o profissional de nutrição sua principal contribuição é na orientação com relação a uma alimentação adequada que possa ser saudável e reduza peso da criança. No entanto, como destacado pela profissional sua contribuição depende do empenho da mesma em realizar as orientações. Desta forma, ressalta que:

[...] todas as crianças que se empenharam e fizeram tudo o que a gente orientou tiveram resultados excepcionais, assim, além do que a gente imaginava e aqueles que não fizeram, não tiveram o mesmo empenho, mantiveram o peso, não engordaram, mas não tiveram resultados satisfatórios.

Este profissional observa as dificuldades com relação à visualização e mensuração dos resultados destacando que não há como saber se a orientação que foi transmitida foi assimilada pelas crianças, desta forma relata que o resultado da sua orientação:

[...] ele não é tangível, você não consegue medir, é intangível. Porque você não sabe quanto àquela criança que não teve resultado naquele ano esta levando para casa e vai refletir aquele resultado daqui a dois, três anos. Então é um resultado totalmente intangivel. Tanto ela quanto os pais e aquelas crianças que tiveram resultados durante um ano de perda de 15 a 20 quilos se ela vai conseguir manter ali durante os próximos anos.

\section{Psicologia}

Segundo o profissional sua maior contribuição é a mudança de comportamento da criança com relação ao ambiente. Desta forma conforme seu relato:

[...] então se eu mudar o ambiente, na verdade eu não vou mudar o ambiente, mas sim o comportamento com relação ao ambiente.

Assim, reflexiona sobre a mudança de comportamento e afirma que:

[...] a disciplina que muda comportamento é a psicologia, não existe outra.

Concluindo que:

[...] o profissional que consegui identificar o comportamento inadequado e mudar esse comportamento é o psicólogo.

\section{Serviço Social}

O acolhimento das famílias é o que o profissional de serviço social julga ser a contribuição importante da sua intervenção no tratamento da obesidade, desta forma as questões que angustiam as famílias, como enfrentar preconceitos, dificuldades, separação 
dos pais, são temas trabalhadas pela referida profissional ao longo do tratamento. A contribuição desta profissional foi resumida neste relato.

o trabalho do serviço social é o de atender essas famílias da maneira que elas possam nos encontros, sentirem-se acolhidos de alguma forma.

Outra contribuição deste profissional é no sentido de levantar questões relevantes para a realização de uma boa intervenção. Devido ao fato de trabalhar direto com as famílias esta profissional investiga as principais dificuldades enfrentadas pelas mesmas. No sentido que elas se sintam acolhidas e ouvidas, visualizando como importante a contribuição do seu trabalho neste sentido.

Sua contribuição é no levantamento de temas como as dificuldades enfrentadas, como separação dos pais, consciência das famílias, futuro das sociedades, enfrentamento do preconceito e participação das famílias no tratamento da criança obesa. A referida profissional ressalta o seu trabalho refletindo que:

sem a visão da família como ela vive hoje, sem esse conhecimento é difícil de trabalhar.

\section{CONSIDERAÇÕES FINAIS}

O conceito de obesidade sofreu uma forte transição, passando a ser estigmatizado nas sociedades contemporâneas industrializadas, inclusive no contexto social, histórico e cultural brasileiro. Atualmente, tais sociedades associam a obesidade ao conceito de risco a saúde e culpam o obeso pela sua condição e responsabilidade de seu tratamento, com o agravamento nas culturas de características lipofóbicas.

A partir da década de 1990, mudanças significativas foram observadas que refletiram nos aspectos culturais, sociais, econômicos e nutricionais das famílias brasileiras refletidas no estilo de vida que passou a ser mais moderno e urbano. Como consequência aumentou-se o consumo de produtos industrializados, especialmente pelas famílias de menor poder aquisitivo.

Em especial entre as crianças, observou-se demasiado consumo de produtos industrializados, horas em frente à televisão e o videogame, ritmo de vida acelerado, poucas políticas públicas e privadas de estímulo à atividade física. Desta forma, Pimenta e Rocha (2012) apontaram que nos últimos anos aumentou-se a porcentagem de crianças entre 5 e 9 anos com sobrepeso e obesidade no Brasil. Assim, delineia-se que essas mudanças na sociedade brasileira foram um processo ocorrido de forma longa, contínua e ininterrupta e com profundo reflexo no atual momento histórico e social.

Com a estigmatização social da obesidade e sua associação à doença, a obesidade constituiu-se como um problema de saúde pública a ser solucionado. Assim, são construídos estereótipos preconceituosos na sociedade e transmitidos pela cultura contribuindo para que a criança desenvolva uma imagem negativa de si. Além disso, momentos repetidos de discriminação ao longo do desenvolvimento infantil podem gerar uma profunda infelicidade chegando, muitas vezes, a casos extremos.

Com relação aos fatores sociais, a violência urbana vivenciada nas periferias dos grandes centros urbanos contribuiu para o esvaziamento das praças públicas e, consequentemente, pode-se contabilizar como uma parcela na contribuição para o aumento dos agravos e dos casos de obesidade infantil, em especial na população de baixa renda.

A obesidade caracteriza-se por ser uma doença multifatorial, atribuídas a fatores, como: genéticos, psicológicos, clínicos, sociais e culturais. Por ser uma doença crônica e de múltiplas causas, ela pode proporcionar algumas limitações na vida da criança em desenvolvimento, assim, as abordagens da equipe multiprofissional devem variar entre intervenções clínicas, psicológicas, nutricionais e estímulos à atividade física, buscando minimizar os sofrimentos e promover qualidade de vida nas esferas biopsicossociais.

Por fim, conforme relatos da equipe multiprofissional, ao longo das suas intervenções, foram observados contribuições, nos aspectos clínicos, sociais, psicológicos, nutricionais e de estímulo à atividade física, contribuindo para o desenvolvimento biopsicossocial das crianças inseridas no programa de tratamento. Desta forma, apontou-se que as intervenções não trazem apenas contribuições nos aspectos biológicos, mas também promovem mudanças nos aspectos psicológicos e sociais das crianças em tratamento.

O presente estudo limitou-se a olhar para um contexto micro, em que ocorrem os processos proximais com vistas ao tratamento da obesidade infantil. Por se tratar de uma questão de saúde pública sugere-se que os estudos futuros devem mirar a obesidade 
para uma perspectiva macro, isto é, no contexto das políticas públicas, pois, podem possibilitar uma ampliação da compreensão dos reflexos nas dimensões micro, nas relações que os profissionais da saúde estabelecem com as crianças nos ambientes em que se privilegia a intervenção direta face a face.

\section{REFERÊNCIAS}

ALMEIDA, G. A. N. et al. Percepção de tamanho e forma corporal de mulheres: estudo exploratório. Psicologia em Estudo, Maringá, v. 10, n. 1, p. 27-35, jan./abr. 2005.

ANDRADE, C. B.; SANTOS, J. Estereotipia de corpos e desenho animado. Revista FIEP Bulletin, Foz do Iguaçu, v. 82, Special Edition, Article II, jan. 2012.

CATTAI, G. B. P. et al. Programa de tratamento multiprofissional da obesidade: os desafios da prática. Revista Ciências, Cuidado e Saúde, Maringá, v. 7, n.1, p. 121-26, jan./mar. 2008.

DÂMASO, A. et al. Etiologia da Obesidade. In: DÂMASO, A. (Org.). Obesidade. Rio de Janeiro: Guanabara Koogan, 2003. p. 3-15.

. Tratamento multiprofissional reduz o tecido adiposo visceral, leptina, grelina e a prevalência de osteatose hepática não alcoólica (NAFLD) em adolescentes obesos. Revista Brasileira de Medicina do Esporte, Niterói, v. 12, n. 5, p. 263-67, set./out. 2006.

FISBERG, M. Obesidade na infância e adolescência. In: FISBERG, M. (Org.). Obesidade: na infância e adolescência. São Paulo: Fundação BYK, 1995. p. 9-13.

FISCHLER, C. Obeso benigno, obeso maligno. In: SANT'ANNA, D. B. (Org.) Políticas do corpo. São Paulo: Estação Liberdade, 1995. p. 69-80.

FRAGOSO, P. A. D. A experiência da regulação das campanhas publicitárias de cigarros como subsídio para a comunicação de alimentos direcionados ao público infantil no Brasil. In: VIVARTA, V. (Org.). Infância e Consumo: estudos no campo da comunicação. Brasília: Instituto Alana, 2009. p. 47-58.

GOMES, I. M. Obesidade como metáfora contemporânea: uma "Cruzada Saudável" em nome do consumo e do risco. Revista Movimento, Porto Alegre, v. 12, n. 03, p. 45-71, set./dez. 2006.

IBGE. Pesquisa de Orçamentos Familiares 2008-2009: Antropométrica e estado nutricional de crianças, adolescentes e adultos no Brasil, Rio de Janeiro, 2010. 130p.

LANCHA JÚNIOR, A. H.; LANCHA, L. O. P. Conceitos de nutrição e exercício relacionados à obesidade. In: LANCHA JÚNIOR, A. H. Obesidade: uma abordagem multidisciplinar. Rio de Janeiro: Guanabara Koogan, 2006. p. 1-14.
LANDEIRO, F. M. Aspectos psicológicos do paciente obeso: um estudo dos sintomas depressivos em portadores de obesidade classes II e III e suas relações com o grau de resiliência. Não Paginada. Disponível em: $<$ http://www.maximoravenna.com.br/wp-content/themes/ ravenna/pdf/fernanda-landeiro.pdf $>$. Acesso em: 21 maio 2011.

MALINA, R. M.; SILVA, R. C. R. Sobrepeso, atividade física e tempo de televisão entre adolescentes de Niterói, Rio de Janeiro, Brasil. Revista Brasileira de Ciência e Movimento, Brasília, v. 11, n. 4, p. 63-66, out./dez. 2003.

MELLO, E. D. et al. Atendimento ambulatorial individualizado versus programa de educação em grupo: qual oferece mais mudanças de hábitos alimentares e de atividade física em crianças obesas? Jornal de Pediatria, Rio Janeiro, v. 80, n. 6, p. 468-474, nov./dez. 2004.

MENDONÇA, C. P.; ANJOS, L. A. Aspectos das práticas alimentares e da atividade física como determinantes do crescimento do sobrepeso/obesidade no Brasil. Caderno de Saúde Pública, Rio de Janeiro, v. 20, n. 3, p. 698-709, mai./ jun. 2004.

MISHIMA,F. K. T. BARBIERI, V. O brincar criativo e a obesidade infantil. Revista Estudos de Psicologia, Natal, v. 14, n. 3, p. 249-255, set./dez. 2009.

MORAES, P. M. Obesidade infantil: Instalação e manutenção, na perspectiva dos pais. 2010. 126 f. Dissertação (Mestrado em Psicologia Clínica) - Programa de Pós-graduação em Psicologia Clínica, Universidade Católica do Pernambuco, Recife, 2010.

OLIVEIRA, C. L. O; FISBERG, M. Obesidade na infância e adolescência: uma verdadeira epidemia. Revista Arquivos Brasileiros de Endocrinologia e Metabologia, São Paulo, v. 47, n. 2, p. 107-108, abr. 2003.

PIMENTA, T. A. M.; ROCHA, R. A Obesidade infantil no Brasil: um estudo comparativo entre a PNSN/1989 e a POF/2008-09 entre crianças de 5 a 9 anos de idade. Revista FIEP Bulletin, Foz do Iguaçu, v. 82, Special Edition, Article I, p, 66-69, jan. 2012.

PINHO, R. A; PETROSKI, E. L. Adiposidade corporal e nível de atividade física em adolescentes. Revista Brasileira de Cineantropometria e Desempenho Humano, Florianópolis, v. 1, n. 1, p. 60-68, jan./dez. 1999.

REIS, C. E. G. et al. Políticas públicas de nutrição para o controle da obesidade infantil. Revista Paulista de Pediatria, São Paulo, v. 29, n. 4, p. 625-633, dez. 2011.

RIGO, L. C.; SANTOLIN, C. B. Combate à obesidade: uma análise da legislação brasileira. Revista Movimento, Porto Alegre, v. 18, n. 2, p. 279-296, abr./jun. 2012.

ROSCHEL, $\mathrm{H}$. et al. Obesidade e atividade física. In: LANCHA JÚNIOR, A. H. Obesidade: uma abordagem 
multidisciplinar. Rio de Janeiro: Guanabara Koogan, 2006. p. 97-124.

SALVE, M. G. C. Obesidade e peso corporal: riscos e consequências. Movimento e Percepção, Espírito Santo do Pinhal, v. 6, n. 8, p. 29-48, jan./jun. 2006.

SANTOS, A. M.; SCHERER, P. T. Política alimentar brasileira: fome e obesidade, uma história de carências. Revista Textos \& Contextos, Porto Alegre, v. 11, n. 1, p. 92-105, jan./jul. 2012.

SEGAL, A.; FANDIÑO, J. Indicação e contra-indicação para realização das operações bariátricas. Revista Brasileira de Psiquiatria, São Paulo, v. 24, n. 3, p. 68-72, dez. 2002.

SILVA, E. L.; MENEZES, E. M. Metodologia da pesquisa e elaboração de dissertação. 4. ed. Florianópolis: UFSC, 2005. 138 p.

SILVA, R. M. F. O Corpo Contemporâneo: modelação e visibilidades. 2007. 143f. Dissertação (Mestrado em Ciências Sociais) Programa de Pós-graduação em Ciências Sociais, Pontifícia Universidade Católica de São Paulo, São Paulo, 2007.
SOCIEDADE BRASILEIRA DE PEDIATRIA. Obesidade na infância e adolescência: Manual de orientação. São Paulo, 2008. 116 p. (acrescentar na referência)

STENZEL, L. M. Obesidade: O peso da exclusão. 1. ed. Porto Alegre: EDIPUCRS, 2002. 124 p.

TSCHOKE, A.; RECHIA, S. O lazer das crianças no bairro Uberaba em Curitiba: a dialética entre os espaços de lazer e a problemática urbana na periferia. Revista Brasileira de Ciências do Esporte, Florianópolis, v. 34, n. 2, p. 263-280, abr./jun. 2012.

VIUNISKI, N. Epidemiologia da obesidade e síndrome plurimetabólica na infância e adolescência. In: DÂMASO, A. Obesidade. Rio de Janeiro: Guanabara Koogan, 2003. p. 16-31.

Recebido em novembro de 2013. Aceito em março de 2014. 